\title{
Technology in World Civilization: A Thousand Year History
}

Editor's Note: For a change of pace, this month's Historical Note reviews a book on the history of technology, Technology in World Civilization: A Thousand Year History, by Armold Pacey (MIT Press, 1990, 225 pages, ISBN: 0-262-16117-6, \$19.95).

"People cannot adopt technologies from other cultures unless they have the skills necessary to modify, adapt, and develop them to suit their own purposes." This theme is brought out again and again in the book, Technology in World Civilization, which is a history not only of the development of technology, but also of its dissemination.

In his third book, Arnold Pacey, author of The Culture of Technology and The Maze of Ingenuity, covers a full millennium of technological development, describing the transfer of ideas and inventions from culture to culture, while keeping the various societal differences and customs and economic pressures firmly in his thoughts. Technology in World Civilization is an informative college-level book, written clearly but densely, with 40 black-and-white illustrations throughout the text.

Pacey's perspective is truly global, tracing in broad strokes how ideas and technology develop. For example, "...sig nificant differences between European and Asian technology arose from the greater stress on mechanical invention in the West as compared with the emphasis on largescale hydraulic works in much of Asia." His refreshing outlook is not obsessed with Western developments to the exclusion of other cultures. Such a balanced view is perhaps the author's greatest achievement.

The sheer number of Pacey's topics is staggering. In just the first two pages I learned that windmills originated in Iran, that iron foundries sprang up in China to keep peasants productive during the growing seasons when they had little work to do in the fields, and that China's major canal systems were built mainly to distribute that iron. I found it difficult to read more than a few paragraphs without stumbling across such fascinating nuggets as: - Ancient Chinese technological inventions were based on belts and pulleys rather than gears.
- Nomadic peoples, with their focus on animal husbandry and wandering, never developed the technology of agricultural implements, nor any of the adjuncts such as irrigation systems or water-powered machinery. They did, however, learn how to make machinery such as large looms portable.

- Silkworm cocoons must be steeped in hot water before the silk strands can be unraveled...which, unfortunately, kills the precious silkworm and increases the cost of further silk production.

- Cotton production and cloth manufacture in Africa was in part caused by the spread of Islam, which required the inhabitants (who normally wore little more than a loincloth) to dress completely from neck to ankle.

- Islamic armies developed a proto-gun weapon called the "fire-lance," which was little more than a bamboo, wood, or metal tube filled with gunpowder, toxic chemicals, and shrapnel. Carried at the end of a lance shaft and ignited, the "fire-lance" would fume and sputter sparks and fragments like a Roman candle for up to five minutes.

- Movable metal type was actually used in Korea as early as 1234, two centuries before Gutenberg created his movable type in Europe. In 1294 Iran employed Chinese printers to produce experimental paper money...but despite this, Islamic society did not adopt printing until about 1720 , long after other parts of the world had depended on it.

- On the American continents, not only had the natives not discovered the wheel, but they also had not learned to make iron tools. However, American crops (potatoes, maize, tomatoes, tobacco, and rubber) had an enormous effect on food production and the standard of living in the rest of the world.

- In 1600 in India, elephants were used to haul newly constructed ships down the slipways into the water.

- The first appearance of steam power in Asia was in river gunboats, not locomotives. The first worldwide application of electricity was in the telegraph.

I found much of this book fascinating. Particularly memorable are the author's discussions of how steel rifle barrels were developed, and how the understanding of machines and mechanical principles (i.e., step-by-step processes and interchangeable parts) dramatically affected how people made their own movements more mechanical, especially in military drills and assembly-line work. Pacey also calls attention to progress, not only because of improved gadgets, but improved management methods as well. "Machines are always used within a framework of organization and management," he writes, "and often there are important organizational changes at the heart of important technological developments."

Unfortunately, the number of topics often left me wondering at the connection between one thought and the next. For instance, in just two pages, (p. 43-44) the narrative hops from the history of weaving, to the creation of paper, to the invention of clocks, to the Crusades, to the discovery of pasta! This is perhaps because Pacey wrote chronologically rather than concentrating on a single item at a time.

Granted, this is a huge, unfocused subject, but at times the brief, almost dismissive descriptions are so short one wonders why they were even mentioned. The development of all forms of aircraft receives one page; the development of the first atomic bomb-one of history's single most enormous concentrated efforts in technology development-receives only four sentences. Technology has been changing so rapidly in the last half-century, though, that a thorough treatment of even these years would require several volumes and is admittedly beyond the scope of Pacey's work.

Technology in World Civilization is not just a history, but is pertinent, describing how technology transfers have affected (and sometimes ruined) cultures not yet ready to receive the innovations. The author also exhibits prior examples of high-tech societies (such as ours) imposing technology on less developed countries.

Arnold Pacey manages to find threads between cultures and historical influences that tie developments together into a "Big Picture" more complex than I had imagined.

KEVIN J. ANDERSON 